\title{
Histopathological pattern of testicular diseases in western Saudi Arabia
}

\author{
Abdulkader M. Albasri, MBBCH, PhD, Akbar S. Hussainy, FCPS (Histopath), PDFPath (Canada).
}

$$
\begin{aligned}
& \text { ABSTRACT } \\
& \text { الأهداف :دراسة الخصائص الهيستوباثولوجية لأمراض الخصية في } \\
& \text { المدينة المنورة. } \\
& \text { الطريقة :أجريت هذه الدراسة في قسم علم الأمراض بأحد }
\end{aligned}
$$

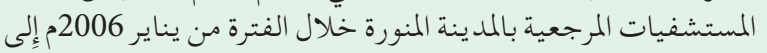

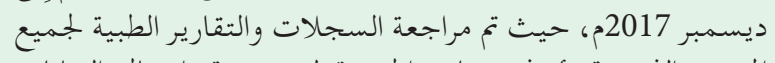

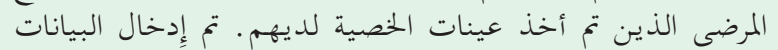

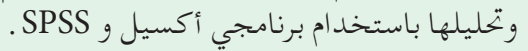

$$
\begin{aligned}
& \text { النتائج :من بين } 199 \text { عينة للخصية وردت، تم أخذ } 108 \text { ( 54.3\% ) }
\end{aligned}
$$

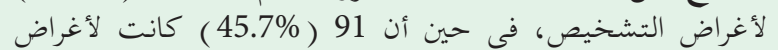

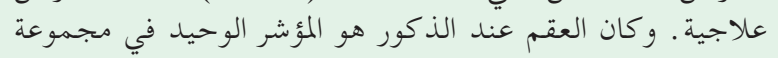

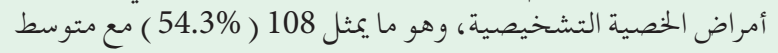

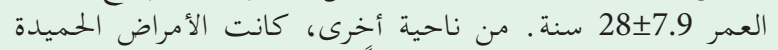

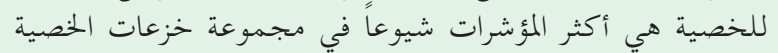

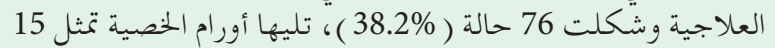

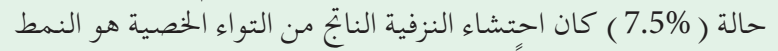

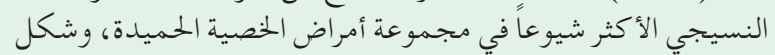

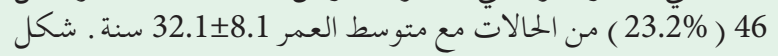

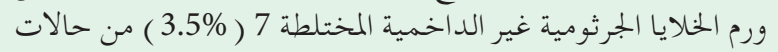

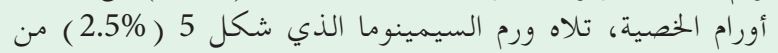

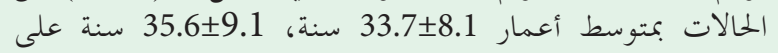

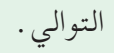

$$
\begin{aligned}
& \text { الخاتمة :توافقت نتائج هذه الدراسة مع الدراسات العالمية والمحلية. }
\end{aligned}
$$

Objectives: To determine the histopathological pattern of testicular diseases among Saudi patients in Madinah, Saudi Arabia.

Methods: This retrospective histopathology-based study was conducted in a tertiary care hospital in Madinah, Saudi Arabia, from January 2006 to December 2017. The data collected were entered into MS-Excel and analyzed using the Statistical Packages for Social Sciences Version 19.
Results: Of the 199 testicular specimens received, 108 $(54.3 \%)$ of the biopsies were taken for diagnostic test, while $91(45.7 \%)$ were for therapeutic test. The male infertility was the only indication in the diagnostic group, accounting for $108(54.3 \%)$ with a mean age of $28 \pm 7.9$ years. Benign conditions of the testes were the most common indication in the therapeutic group accounting for 76 cases $(38.2 \%)$, followed by 15 cases (7.5\%) of testicular tumors. Hemorrhagic infarction from testicular torsion was the most common histologic patterns in benign testicular conditions group, accounting for $46(23.2 \%)$ of the cases with a mean age of patients $32.1 \pm 8.1$ years. Mixed non-seminomatous germ cell tumor was the most common primary tumor in $7(3.5 \%)$ cases, followed by seminoma occurring in $5(2.5 \%)$ cases. Mean ages for these patients were $33.7 \pm 8.1$ years for primary tumor and 35.6 \pm 9.1 years for seminoma.

Conclusions: The pattern of testicular diseases on the basis of histopathology experience in the Madinah region appears to conform to world literature and KSA.

Saudi Med J 2018; Vol. 39 (5): 476-480 doi: $10.15537 /$ smj.2018.5.22142

From the Department of Pathology, Taibah University, Madinah, Kingdom of Saudi Arabia.

Received 8th February 2018. Accepted 11th April 2018.

Address correspondence and reprint request to: Dr. Abdulkader $M$. Albasri, Associate Professor, Department of Pathology, Taibah University, Madinah, Kingdom of Saudi Arabia.E-mail:abdbasri@hotmail.com

$\mathrm{T}$ esticular biopsy and histopathological examination are very important approaches to arrive at definitive diagnosis of many diseases, including a crucial role in male primary infertility. ${ }^{1}$ Recently testicular biopsies have been used for testicular sperm extraction in patients of primary infertility. ${ }^{2}$ Moreover histological examinations of surgical specimens namely, orchiectomies are also equally essential in testicular tumor pathology as well 
as for exclusion of premalignant conditions. Torsions, cryptorchidism, inflammations, and testicular tumors all belong to the broad category of differential diagnosis of chronic orchialgia and constitute a significant proportion of urology clinical practice. ${ }^{3}$ The prevalence and incidence of testicular tumors are not particularly high around the globe. During the year 2016, there were only less than 9,000 new cases of testicular cancer in the whole United States. ${ }^{4}$ It is specifically rare in Africa ${ }^{5,6}$ and Middle Eastern Asia. ${ }^{7,8}$ Recently, a number of histological studies for disease patterns have been published in the peer-reviewed scientific literature from Madinah region of Kingdom of Saudi Arabia (KSA) addressing major human body systems such as breast, ${ }^{9,10}$ gastrointestinal tract, ${ }^{11-14}$ and urinary tract; ${ }^{15,16}$ as well as thyroid ${ }^{17}$ and lymph nodes. ${ }^{18}$

The objective of our study is to observe the pattern of testicular disease, as experienced in the histopathology department of a tertiary care hospital of Madinah; and privileged to have a large patient catchment area of the western region of KSA.

Methods. This retrospective study included histopathological reports of all patients with testicular diseases who had undergone testicular biopsies (92 cases) and surgical orchiectomies (107 cases) between January 2006 and December 2017 at the King Fahad Hospital, Madinah, Saudi Arabia. Diagnosis of testicular tumors was made only in the orchidectomy specimens, on clinical grounds and radiological examinations, which was performed in the urology outpatient clinic. The specimens were preserved in $10 \%$ buffered formalin as fixative and read by a consultant pathologist after routine slide staining with hematoxylin and eosin stain. The data collected from the records of the histopathology department included age of the patients, indication for the biopsy and the final histology report were analyzed using the Statistical Package for Social Sciences software version 19 (SPSS Inc, Chicago, IL, USA). The only exclusion criteria was non-Saudi (expatriate) patients, who underwent the testicular biopsies or orchidectomy procedures.

For prior related research, services of general search engines namely Google search and MSN Bing search engine were utilized; as well as specific medical search engine Pubmed/Medline, Science Direct, Scopus and

Disclosure. Authors have no conflict of interests, and the work was not supported or funded by any drug company.
Google scholar were used. The present study was a retrospective research involving the histopathology record and did not touch the patients personal information or implicate upon the management, thus was according to the principles of Helsinki Declaration.

Results. One hundred and ninety-nine patients with testicular biopsies were received at the Department of Pathology, King Fahad Hospital, Madinah, Saudi Arabia from January 2006 to December 2017. Their age ranged from 5 to 96 years with a mean age of $29.4 \pm 7.2$ years. One hundred and forty-four patients had unilateral and 55 patients had bilateral testicular biopsies.

Table 1 shows the frequency and percentages of common indications for testicular biopsy and summary of breakdown. Male infertility was the most common indication accounting for more than half of patients.

The mean age of patients with male infertility group was $28 \pm 7.9$ years (range 13-50); and the most

Table 1 - Common indications for testicular biopsy.

\begin{tabular}{lcrr}
\hline Indication & $\begin{array}{c}\text { Histopathologic } \\
\text { diagnosis }\end{array}$ & n & $(\%)$ \\
\hline Diagnostic & Male infertility & 108 & $(54.3)$ \\
Therapeutic & Benign testicular diseases & 76 & $(38.2)$ \\
& testicular tumors & 15 & $(7.5)$ \\
Total & & 199 & $(100)$ \\
\hline
\end{tabular}

Table 2 - Histological diagnoses, frequencies, percentages and mean ages of all testicular specimens $(n=199)$.

\begin{tabular}{lrrc}
\hline Histopathologic diagnosis & n (\%) & $\begin{array}{c}\text { Mean age } \\
\text { (years) }\end{array}$ \\
\hline Male infertility (n=108) & 45 & $(22.7)$ & 26.3 \\
$\quad$ Hypospermatogenesis & 32 & $(16.1)$ & 31.3 \\
$\quad$ Sertoli cell only syndrome & 17 & $(8.5)$ & 29.6 \\
$\quad$ Complete spermatogenic arrest & 9 & $(4.5)$ & 14.8 \\
$\quad$ Testicular atrophy & 5 & $(2.5)$ & 35.6 \\
$\quad$ Tubular hyalinization & & & \\
Benign testicular diseases (n=76) & 46 & $(23.2)$ & 32.1 \\
$\quad$ Testicular torsion & 17 & $(8.5)$ & 27.6 \\
Inflammatory conditions & 13 & $(6.5)$ & 19.0 \\
$\quad$ Cryptorchidism & & & \\
Testicular tumors ( $n=15)$ & & & \\
$\quad$ Primary tumors & 7 & $(3.5)$ & 33.7 \\
$\quad$ Mixed nsgct & 5 & $(2.5)$ & 35.6 \\
$\quad$ Seminoma & 1 & $(0.5)$ & 31.0 \\
$\quad$ Mature cystic teratoma & 1 & $(0.5)$ & 16.0 \\
$\quad$ Adenomatoid tumor of the & & & \\
$\quad$ epididymis & & & \\
Secondary tumors & 1 & $(0.5)$ & 21.0 \\
$\quad$ Diffuse large b-cell nhl & 199 & $(100)$ & \\
Total & &
\end{tabular}


common histologic pattern in this group was hypo spermatogenesis (Table 2). The mean age of patients with benign testicular conditions was $31.5 \pm 7.8$ years (range 5-96 years). Hemorrhagic infarction from testicular torsion was the most common histologic pattern in this group (Table 2).

The age of patients with testicular tumors ranged from 16 to 70 years with a mean age of $38.2 \pm 9.5$ years. Primary tumors of the testes accounted for 93.3\% of testicular tumors and the most common primary malignant tumor of the testis was mixed non-semi nomatous germ cell tumor (Table 2).

Discussion. Testicular biopsy has been conventionally used as an important procedure in the diagnosis and management of infertility. Radiologically guided testicular biopsy is a less invasive method of obtaining specimen for histological diagnosis; ${ }^{19}$ however, open biopsies or orchidectomies have also been performed, frequently in difficult cases, inflammatory conditions and testicular tumors, accounting for substantial workload on the histopathologist. Recently, robotic assisted surgery has also been introduced in andrological surgical practices. ${ }^{20}$ Excisional surgery of the testis is also therapeutically indicated for benign conditions of the testis such as infarctions of testicular torsion, testicular atrophy in cryptorchidism, or in chronic epididymo orchitis irresponsive to traditional treatments. ${ }^{5}$

During the study period, we reported 108 cases of primary infertility; the mean age of patients who underwent testicular biopsies for male infertility was 28 \pm 7.9 years (range 13-50). A study on testicular biopsies from Zaria, Nigeria in their 472 cases, reported a mean age of 31 years, ${ }^{21}$ whereas a group from Lagos Nigeria reported a mean age of 30 years. ${ }^{22}$ A group of Pakistani scientists in their study on evaluation of azoospermia and testicular biopsies reported a mean age of 28 years. ${ }^{23}$ From within the KSA, a study from the city of Jeddah reported a mean age of 24.5 years. ${ }^{24}$ Most of the studies cited in the discussion appear to observe a mean age above 30 years including this present study, suggesting a possibility that the female partners have to go through detailed investigations before the male partner is submitted to the invasive procedure of testicular biopsies. However, in one study from Jeddah, KSA that observed a younger mean age of less than 25 years, this difference as well as many other observed differences in their study as compared with other studies have not been well understood. ${ }^{24}$ On the basis of age range, we also noted testicular biopsy for infertility, carried out at a very young age of 13; most likely due to typographic error or other errors of recording, beyond our control.

In the present study, we found hypospermatogenesis to be the most common pattern of histology accounting for $22.7 \%$ cases. Ahmed and Bello from Zaria, Nigeria in their 472 cases, also found hypospermatogenesis to be the most frequent histology accounting for $35.2 \%$ of their cases. ${ }^{21}$ Whereas a scientists from Lagos, Nigeria, found a testicular atrophy in $30(58.8 \%)$ as the most common diagnosis. ${ }^{22}$ In the same year, Parikh et al from India reported Sertoli cell only syndrome (SCOS) to be the most common abnormal histopathological finding accounting for $18.75 \%$ of their cases. ${ }^{25}$ Similar was the observation by a group from Pakistan, who observed SCOS in $30.2 \%$ of their cases. ${ }^{23}$ There is only one recent study on the histological patterns of testicular biopsies from KSA, in which Abdulla and Bondagji from Jeddah, also found hypospermatogenesis to be most frequent, accounting for $29 \%$ of their cases. ${ }^{24}$ Although different observations have been reported from recent studies from a number of geographical regions, hypospermatogenesis appears to be the most common diagnosis reported by most of them and our observations are in concordance with other studies including the study from KSA.

In our experience, hemorrhagic infarction from testicular torsion accounted for about a quarter of all cases ( 46 out of 199 cases). Although these figure appear to be high, our study is only a hospital-based pathology data and is obviously biased by the local practices of the urology surgeons. However, this condition is quite rare and figures of as low as 1.1 per 100,000 have been reported recently from Korea. ${ }^{26}$ The cause or the precipitating factor of torsion is usually not detectable, in majority of cases; however, in rare instances trauma has been reported to be the underlying factor. ${ }^{27}$

We also found complete hemorrhagic infarction in all our patients of torsion of testis. Recently from Central KSA, a case of torsion of testis in an elderly 63 year old patient, was found to have a seminoma as the underlying cause. ${ }^{28}$ Torsion of testis is predominantly a disease of young age, with highest incidence reported in adolescent age group. ${ }^{26}$ The mean age of our torsion was 32.1 \pm 8.1 years (range 15-91 years). Case reports of testicular torsion in extremes of ages have been reported in the medical literature at the age of 67 years age from UK. ${ }^{29}$ One of our patient was 91 year old, but we do not have any clinical history, investigations or follow-up to present and publish it as a case report in the medical literature. Cryptorchidism considered as the most 
common anomaly of genitourinary tract accounting for $3 \%$ cases in full term boys. ${ }^{30}$ In our experience too, cryptorchidism accounted for about $10 \%$ of total cases (22 out of 199 cases). This is a condition of newborns and infants, and a delay in surgery can lead to infertility and high risk of testicular cancers. At most centres, the target for surgery is within one year. ${ }^{31}$ In the present study, patients of cryptorchidism had a mean age of $19 \pm 4.7$ years (range 15-39 years). The possible explanation of this gross difference in the age at presentation and performance of surgery can be explained by lack of education and possible problems with access to treatment. Interestingly, none of the cases revealed any premalignant or malignant lesion on histological examination of the orchidectomy specimens. These aspects of our observation need to be followed up in well-designed prospective clinicopathological studies.

In our experience, there were 12 cases of malignant primary testicular tumors, accounting for only about $6 \%$ of our testicular histopathology workload. Although these figures are quite low, nonetheless are in conformation with world literature, which report its rarity especially in Asian populations; ${ }^{6}$ as well as from the KSA. ${ }^{7,8}$ Scientists from London, analyzing the global incidence of testicular cancer have reported its incidence rate to be highest in New Zealand and lowest in India. ${ }^{32}$ Researcher from Denmark found testicular cancer to be a rare disease, with approximately 300 cases per year in their whole country, although it was the most common cancer in men aged 20 to 40 years. ${ }^{33}$ Similarly, Assi et $\mathrm{al}^{6}$ from Lebanon report a mean age of 32 years in their testicular tumor patients. The finding of these studies are also endorsed locally by the Saudi Cancer registry (published in September 2017) which reported testicular cancer as a rare tumor, with only 98 new testicular cancers reported in $2014 .^{34}$ The age of our patients with testicular tumors ranged from 16 to 70 years with a mean age of $38.2 \pm 9.5$ years. Although the number of testicular cancer patients are low; our observation are in conformation with figures reported from the global, regional, and national studies.

The limitations of the study were the possible errors of data recording (such as age), which were not within our control, as it was a retrospective study. Moreover, due to very low number of testicular malignancies, in-depth discussion on malignancies and any meaningful epidemiological conclusion could not be made.

In conclusion, our observation of testicular histopathology pattern appears to be similar to the reported world literature as well as from the KSA. Minor differences in age range appear to be due to limitations of retrospective study such as improper recording of data or possibly lack of education in the rural population, leading to late presentation to the hospitals.

Acknowledgment. We hereby acknowledge the cooperation of Dr. A. Hujaily, the Head of Pathology Department, King Fahad Hospital, Madinah, Kingdom of Saudi Arabia, for his uncountable support in using his departmental facilities and permission to collect laboratory data. Furthermore, we would like to thank Scribendi, the Editing and Proofreading Services for English Documents (https://www. scribendi.com/) for the English language editing of the manuscript.

\section{References}

1. Siadati S, Shafi H, Ghorbani H. Testicular Biopsy in Males With Infertility: A Longitudinal Study. Iran J Pathol 2017 Spring; 12: 177-182.

2. DadkhahF, Hosseini SJ, SadighiGilani MA, Farrahi F, Amini E, Kazeminejad B. Optimal number of biopsies and impact of testicular histology on the outcome of testicular sperm extraction. Urol J 2013; 10: 795-801.

3. Sigalos JT, Pastuszak AW. Chronic orchialgia: epidemiology, diagnosis and evaluation. TranslAndrol Urol 2017; 6 (Suppl 1): S37-S43.

4. Smith ZL, Werntz RP, Eggener SE. Testicular Cancer: Epidemiology, Diagnosis, and Management. Med Clin North Am 2018; 102: 251-264.

5. Oranasi CK, Onyiaorah IV, Ukah CO. Pattern of testicular biopies as seen in a Tertiary Institution in Nnewi, Southeast Nigeria. Nigerian Journal of Surgery 2014; 20: 55-58.

6. Assi T, Rassy M, Nassereddine H, Sader-Ghorra C, Abadjian G, Ghosn M, et al. Distribution of testicular tumors in Lebanon: a single institution overview. Asian Pac J Cancer Prev 2015; 16 : 3443-3446.

7. Abomelha M. Adult testicular cancer: Two decades of Saudi national data. Urol Ann 2017; 9: 305-309.

8. Abomelha M. Pediatric testicular cancer: Two decades of Saudi national data. Urol Ann 2017; 9: 310-314.

9. Albasri AM. Profile of benign breast diseases in western Saudi Arabia. An 8-year histopathological review of 603 cases. Saudi Med J 2014; 35: 1517-1520.

10. Albasri A, Hussainy AS, Sundkji I, Alhujaily A. Histopathological features of breastcancer in Al-Madinah region of Saudi Arabia. Saudi Med J 2014; 35: 1489-1493.

11. Elsawaf ZM, Albasri AM, Hussainy AS, Alhujaily AS. Histopathological pattern of benign endoscopic gastric biopsies in Western Saudi Arabia: A review of 1236 cases. J Pak Med Assoc 2017; 67: 252-255.

12. Albasri AM. Histopathological profile of benign colorectal diseases in Al-Madinah region of Saudi Arabia. Asian Pac J Cancer Prev 2014; 15: 7673-7677.

13. Albasri A, Yosef H, Hussainy AS, Sultan SA, Alhujaily A. Histopathological features of colorectal cancer in Al-Madinah region of Saudi Arabia: 8 years experience. Asian Pac J Cancer Prev 2014; 15: 3133-3137.

14. Albasri A, Yosef H, Hussainy A, Bukhari S, Alhujaily A. Profile of colorectal polyps: a retrospective study from King Fahad Hospital, Madinah, Saudi Arabia. Asian Pac J Cancer Prev 2014; 15: 2669-2673. 
15. El-Siddig AA, Albasri AM, Hussainy AS, Alhujaily AS. Urinary bladder cancer in adults: a histopathological experience from Madinah, Saudi Arabia. J Pak Med Assoc 2017; 67: 83-86.

16. Albasri A, El-Siddig A, Hussainy A, Mahrous M, Alhosaini AA, Alhujaily A. Histopathologic characterization of prostate diseases in Madinah, Saudi Arabia. Asian Pac J Cancer Prev 2014; 15: 4175-4179.

17. Albasri A, SawafZ, Hussainy AS, Alhujaily A. Histopathological patterns of thyroid disease in Al-Madinah region of Saudi Arabia. Asian Pac J Cancer Prev 2014; 15: 5565-5570.

18. Albasri AM, El-Siddig AA, Hussainy AS, Alhujaily AS. Pattern of lymph node pathology in western Saudi Arabia. Asian Pac J Cancer Prev 2014; 15: 4677-46781.

19. Velasquez M, Tanrikut C. Surgical management of male infertility: an update. Transl Androl Urol 2014; 3: 64-76.

20. Parekattil SJ, Gudeloglu A. Robotic assisted andrological surgery. Asian J Androl 2013; 15: 67-74.

21. Ahmed A, Bello A. Role of testicular biopsy in the evaluation of male infertility. African J Urol 2007; 13: 107-111.

22. Ikuerowo SO, Izegbu MC, Benebo AS, Fadeyibi IO, Omodele FO. Testicular biopsies of azoospermic men at The Lagos State University Teaching Hospital. African J Urol 2010; 16: 69-72.

23. Mushtaq H, Alam S, Khan MA. Histopathological patterns of testicular biopsies in male infertility. Journal of Islamabad Medical \& Dental College 2013; 2: 81-86.

24. Abdullah L, Bondagji N. Histopathological patterns of testicular biopsy in male infertility: A retrospective study from a tertiary care center in the western part of Saudi Arabia. Urol Ann 2011; 3: 19-23.

25. Parikh UR, Goswami HM, Deliwala KJ, Shah AM, Barot HP. Testicular biopsy in male infertility: Study of 80 cases. Journal International Medical Sciences Academy 2012; 25: 75-77.
26. Lee SM, Huh JS, Baek M, Yoo KH, Min GE, Lee HL, et al. A nationwide epidemiological study of testicular torsion in Korea. J Korean Med Sci 2014; 29: 1684-1687.

27. Sharp VJ, Kieran K, Arlen AM. Testicular torsion: diagnosis, evaluation, and management. Am Fam Physician 2013; 88: 835-840.

28. Alrabeeah K, Aljuhayman A, Abumelha S, Alkhamees M, Aloudah N. Intra-scrotal testicular torsion of a classical seminoma in an elderly patient: a case report and literature review. J Surg Case Rep 2017; 7: 1-3.

29. Farrington NL, Lucky MA, Barnes T, Calvert R. Confirmed testicular torsion in a 67 year old. J Surg Case Rep 2014; 8: 2014.

30. Sepúlveda X, Egaña PL. Current management of non-palpable testes: a literature review and clinical results. Transl Pediatr 2016; 5: 233-239.

31. Wei Y, Wu SD, Wang YC, Lin T, He DW, Li XL, et al. A 22-year retrospective study: educational update and new referral pattern of age at orchidopexy. BJU Int 2016; 118 : 987-993.

32. Shanmugalingam T, Soultati A, Chowdhury S, Rudman S, Van Hemelrijck M. Global incidence and outcome of testicular cancer. Clin Epidemiol 2013; 5: 417-427.

33. Daugaard G, Kier MG, Bandak M, Mortensen MS, Larsson H, Søgaard M, et al. The Danish Testicular Cancer database. Clinical Epidemiology 2016; 8: 703-707.

34. Saudi Health Council. Saudi Cancer Registry. Cancer Incidence Report, Saudi Arabia 2014 [Update 2017; Accessed 2018 January 30]. Available from: http://www. chs.gov.sa/Ar/HealthCenters/NCC/CancerRegistry/ CancerRegistryReports/2014.pdf. 